\title{
Effect of Aerobic Exercise Training on Ventilatory Efficiency and Respiratory Drive in Obese Subjects
}

\author{
Mehdi Chlif PhD, Anis Chaouachi PhD, and Said Ahmaidi PhD
}

\begin{abstract}
BACKGROUND: Obese patients show a decline in exercise capacity and diverse degrees of dyspnea in association with mechanical abnormalities, increased ventilatory requirements secondary to the increased metabolic load, and a greater work of breathing. Consequently, obese patients may be particularly predisposed to the development of respiratory muscle fatigue during exercise. The aim of this study was to assess inspiratory muscle performance during incremental exercise in 19 obese male subjects (body mass index $41 \pm 6 \mathrm{~kg} / \mathrm{m}^{2}$ ) after aerobic exercise training using the noninvasive, inspiratory muscle tension-time index $\left(T_{T 0.1}\right)$. METHODS: Measurements performed included anthropometric parameters, lung function assessed by spirometry, rate of perceived breathlessness with the modified Borg dyspnea scale (0-10), breathing pattern, maximal exercise capacity, and inspiratory muscle performance with a breath-by-breath automated exercise metabolic system during an incremental exercise test. $T_{\text {T0.1 }}$ was calculated using the equation, $T_{T 0.1}=P_{0.1} / P_{\text {Imax }} \times T_{I} / T_{\text {tot }}$ (where $P_{0.1}$ represents mouth occlusion pressure, $P_{I m a x}$ is maximal inspiratory pressure, and $T_{I} / T_{\text {tot }}$ is the duty cycle). RESULTS: At rest, there was no statistically significant difference for spirometric parameters and cardiorespiratory parameters between pre- and post-training. At maximal exercise, the minute ventilation, the rate of exchange ratio, the rate of perceived breathlessness, and the respiratory muscle performance parameters were not significantly different pre- and posttraining; in contrast, tidal volume $(P=.037$, effect size $=1.51)$, breathing frequency $(P=.049$, effect size $=0.97)$, power output $(P=.048$, effect size $=0.79)$, peak oxygen uptake $(P=.02$, effect size $=0.92$ ) were significantly higher after training. At comparable work load, training induces lower minute ventilation, mouth occlusion pressure, ratio of occlusion pressure to maximal inspiratory pressure, $T_{\mathrm{T} 0.1}$, and rate of perceived breathlessness. CONCLUSIONS: Aerobic exercise at ventilatory threshold can induce significant improvement in respiratory muscle strength, maximal exercise capacity, and inspiratory muscle performance and decreased dyspnea perception in obese subjects. Key words: aerobic exercise; ventilatory efficiency; exercise capacity; dyspnea; maximal inspiratory pressure; mouth occlusion pressure. [Respir Care 2017;62(7):936-946. () 2017 Daedalus Enterprises]
\end{abstract}

\section{Introduction}

In obese subjects, the inspiratory muscles are faced with a greater load, which impels a threshold load at rest or

\footnotetext{
Drs Chlif and Ahmaidi are affiliated with EA-3300 :APERE, Exercise Physiology and Rehabilitation Laboratory, Picardie Jules Verne University, Sport Sciences Department, Avenue Paul Claudel, F-80025, Amiens Cedex, France. Drs Chlif and Chaouachi are affiliated with the Tunisian Research Laboratory "Sport Performance Optimisation", National Center of Medicine and Science in Sports (CNMSS), Tunis, Tunisia.
}

The authors have disclosed no conflicts of interest. during exercise. ${ }^{1}$ Ventilatory limitation and the associated respiratory discomfort contribute to exercise intolerance

\footnotetext{
Correspondence: Mehdi Chlif PhD, Tunisian Research Laboratory "Sport Performance Optimisation", National Center of Medicine and Science in sports (CNMSS), Tunis, Tunisia and EA-3300 :APERE, Exercise Physiology and Rehabilitation laboratory, Picardie Jules Verne University, Sport Sciences department, Avenue Paul Claudel, F-80025, Amiens Cedex, France. E-mail: mehdi.chlif@gmail.com.
}

DOI: $10.4187 /$ respcare. 04923 
in obese patients. ${ }^{1-3}$ Exercise intolerance has been associated with several respiratory abnormalities, including decline of lung function; ${ }^{4}$ increased work and $\mathrm{O}_{2}$ cost of breathing during exercise ${ }^{5}$ considerable influence on respiratory responses; dynamic changes in lung volume during exercise; ${ }^{2}$ expiratory flow limitations; ${ }^{1}$ impaired ventilatory efficiency; $;, 7$ alterations in central ventilatory drive and in dynamic ventilatory mechanics that might explain the increased breathlessness during exercise; 3,8 and impaired exercise capacity, mainly due to an elevation in blood carboxyhemoglobin levels, which reduces the oxygen-carrying capacity of blood and lead to relative tissue hypoxia. ${ }^{9}$

Obese patients tend to have an increased ventilatory drive, ${ }^{3}$ which corresponds to their increased effort to breathe; ${ }^{10}$ dyspnea; and decreased exercise capacity. ${ }^{11}$ Hence, obese patients may be particularly predisposed to the development of inspiratory muscle fatigue during exercise.

There are several ways to assess respiratory muscle function. ${ }^{12}$ Volitional methods measure maximal respiratory pressures, whereas non-volitional methods measure respiratory muscle electrical activity ${ }^{12}$ (power spectral analysis, integrated electrical activity, or some combination of these two). The tension-time index $\left(\mathrm{T}_{\mathrm{T} 0.1}\right)$ measured at the mouth in spontaneous breathing during exercise is a useful, noninvasive, and reproducible measurement of overall inspiratory muscle activity. ${ }^{3,13}$ It may be useful in our understanding of the influence of endurance training on inspiratory muscle performance. The physiological adaptations to endurance training, both central (cardiorespiratory) and peripheral (local musculature), are well known. ${ }^{14}$ Exercise training contributes to decreasing ventilatory demand and probably limits the effects of ventilatory constraints on exercise capacity and may be a way to increase inspiratory muscle function. ${ }^{6,7}$ Exercise training has been shown to improve exercise performance (ie, distance achieved) on the 6-min walk test ${ }^{15}$ and ventilatory efficiency (ie, ventilatory equivalent method or $\dot{\mathrm{V}}_{\mathrm{E}} / \dot{\mathrm{V}}_{\mathrm{O}_{2}}$ ) and to decrease exertional breathlessness in obese children and adolescents. ${ }^{7}$ There is controversy over the specific effects of physical training on respiratory muscle performance in obese patients. For these reasons, aerobic exercise training could be justified as a strategy with potential clinical benefits in obese patients.

To our knowledge, the effects of aerobic exercise training on inspiratory muscle performance by using $\mathrm{T}_{\mathrm{T} 0.1}$ (given by $\mathrm{P}_{0.1} / \mathrm{P}_{\text {Imax }} \times \mathrm{T}_{\mathrm{I}} / \mathrm{T}_{\text {tot }}$, where $\mathrm{P}_{0.1}$ represents mouth occlusion pressure, $\mathrm{P}_{\text {Imax }}$ is maximal inspiratory pressure, and $T_{I} / T_{\text {tot }}$ is the duty cycle) in adult obese subjects are yet to be examined. We hypothesized that after 8 weeks of exercise training, inspiratory muscle activity and dyspnea would decrease and that improved inspiratory muscle performance would be associated with improved exercise tolerance.

\section{QUICK LOOK}

\section{Current knowledge}

Obesity included an amplified demand for ventilation, higher work of breathing, respiratory muscle inefficiency, oxygen consumption, and respiratory energy expenditure. All these factors lead to impaired exercise capacity, dyspnea, and fatigue perception in obese subjects. Controversy exists on the specific effects of endurance exercise training at ventilatory threshold on respiratory muscle performance in obese subjects.

\section{What this paper contributes to our knowledge}

The results from this study may enhance the understanding of the mechanisms leading to improved exercise capacity after aerobic endurance exercise training. Following 8 weeks of exercise training at ventilatory threshold, inspiratory muscle efficiency, dyspnea perception, breathing pattern and exercise tolerance were improved in obese subjects.

\section{Methods}

\section{Subjects}

This study was carried out in 19 obese men (age $47 \pm 14 \mathrm{y}$ ) with a body mass index of $41 \pm 6 \mathrm{~kg} / \mathrm{m} .^{2}$ The experimental procedures complied with the ethical standards of the 1975 Helsinki Declaration, and approval was received from the appropriate local institutional review board. From the 60 patients registered with obesity screened at the out-patient clinic of the Department of Metabolic Disorders and Hypertension, Corbie Hospital France, 19 subjects were enrolled.

All qualified participants were familiarized with exercise on the cycle ergometer and instructed to avoid exercise, food, and caffeine for at least $2 \mathrm{~h}$ before exercise testing, and they had not participated in regular vigorous exercise for the previous 6 months. The American Thoracic Society spirometry interpretation workshop only states that patients should be "never-smokers, free of respiratory symptoms and disease."16,17 Patients who did not meet these criteria were excluded.

\section{Body Composition}

The anthropometric measurements included height and weight. Subjects were measured in light clothing and barefooted. Height and weight were both measured in the standing position. Height was measured with a stadiometer (Hol- 
tain, Ales, UK), and weight was measured with a digital electronic scale (Soehnle, Murrhardt, Germany).

\section{Pulmonary Function Test}

The pulmonary function test was performed using the CPX/D System (Medical Graphics Corporation, St Paul, Minnesota), with flow measurement carried out using a calibrated pneumotachograph (Fleish, Lausanne, Switzerland). The subjects completed at least 3 acceptable maximal forced expiratory maneuvers; technical procedures, acceptability, and reproducibility criteria corresponded to the recommendations of the American Thoracic Society/European Respiratory Society. ${ }^{18,19} \mathrm{FVC}, \mathrm{FEV}_{1}$, and peak expiratory flow were recorded at body temperature and ambient pressure and saturated with water vapor. Predictive values were taken from Castellsagué et al. ${ }^{20}$

\section{Calculation of $\mathbf{P}_{\mathbf{0 . 1}}$}

$\mathrm{P}_{0.1}$ is the maximal pressure developed during a spontaneous respiratory effort during a 100 -ms occlusion at the beginning of inspiration. ${ }^{21,22}$ Its timing is such that it is not influenced by the conscious response to occlusion, and as an index of the ventilatory drive, it has the advantage over ventilation of being independent of the mechanical properties of the lung. ${ }^{22} \mathrm{P}_{0.1}$, a valid index of neural output, was assessed at the level of functional residual capacity (FRC). ${ }^{21}$

Subjects were asked to breathe quietly, with the nose occluded, through a mouthpiece connected to the pneumotachograph (Fleish) with a 2-way low- resistance breathing valve $\left(0.9 \mathrm{~cm} \mathrm{H}_{2} \mathrm{O} / \mathrm{L} / \mathrm{s}\right.$, dead space of $50 \mathrm{~mL}$, model 9340 occlusion valve, Hans Rudolph, Kansas City, Missouri). During the exhalation phase of breathing, a balloon was rapidly inflated in the inspiratory limb of the breathing circuit to occlude the following inspiratory flow. It was closed during expiration and automatically opened about $150 \mathrm{~ms}$ after the onset of the subsequent inspiration. The pressure generated during the first $100 \mathrm{~ms}$ represents the force generated by the inspiratory muscles in isometric conditions under the same respiratory neural stimulus as an unobstructed breath. ${ }^{21} \mathrm{P}_{0.1}$ was measured with a differential pressure transducer (LPM 9000 series, $\pm 50 \mathrm{~cm}$ $\mathrm{H}_{2} \mathrm{O}$, Druck, Leicester, United Kingdom). The balloon was inflated with helium from a small gas cylinder, and the valve was controlled manually with a tiny switch. The subject was asked to continue to breathe normally despite the occlusions. Throughout the maneuver mentioned previously, the subject wore headphones and listened to music to dampen any noise from the switching device controlling the balloon and could see neither the occlusion valve nor the operator and therefore was unable to anticipate the airway occlusion. The Lab View interface (Lab View, National Instruments Corporation, Austin, Texas), which provided visual feedback, was used to identify the onset of inspiration. At rest, maneuvers were made until 5 technically satisfactory and reproducible measurements were obtained (variation $<10 \%$ ). ${ }^{22}$ The highest score was kept for analysis.

\section{Calculation of $\mathbf{P}_{\text {Imax }}$}

$\mathrm{P}_{\text {Imax }}$ is the force that respiratory muscles are able to generate during an occlusive maneuver at prefixed volume. ${ }^{23} \mathrm{P}_{\text {Imax }}$ was measured at the FRC (the effect of variation of muscle length on force development should be minimal near FRC, where the isometric force length curve of the diaphragm is nearly flat), with a differential pressure transducer (LPM 9000 series, $\pm 350 \mathrm{~cm} \mathrm{H}_{2} \mathrm{O}$ ) using the technique of Black and Hyatt. ${ }^{24}$ All subjects had no previous experience of these maneuvers. Therefore, great care was taken to fully explain the procedures. This was facilitated by the use of an oscilloscope (Gould, Cleveland, Ohio), which provided visual feedback to the subjects during the explanations and during the maneuvers. Subjects breathed comfortably on the experimental apparatus without the air-flow resistor in place. After a steady state FRC was attained, the inspiratory and expiratory ports were occluded at end exhalation with a balloon shutter valve, and the subject was asked to perform a maximal inspiratory effort. The shutter valve opened automatically after $5 \mathrm{~s}$, and the highest inspiratory pressure that was sustained for $\geq 1 \mathrm{~s}$ was taken as the $\mathrm{P}_{\mathrm{Imax}}$. Maneuvers were made until 3 technically satisfactory and reproducible measurements were obtained (variation $<5 \%$ ). The highest score was kept for analysis. The maneuvers were performed in the sitting position before and immediately after exercise test. For the sake of convenience, $\mathrm{P}_{\text {Imax }}$ was expressed in positive values.

\section{Derived Parameters}

The breathing pattern was determined from an average of 10 respiratory cycles. Tidal volume $\left(\mathrm{V}_{\mathrm{T}}\right)$, inspiratory time $\left(T_{I}\right)$, and total time of the respiratory cycle $\left(T_{\text {tot }}\right)$ were measured. Then we calculated breathing frequency (f); minute ventilation $\left(\dot{\mathrm{V}}_{\mathrm{E}}\right)$; duty cycle $\left(\mathrm{T}_{\mathrm{I}} / \mathrm{T}_{\text {tot }}\right)$, which represents the time fraction during which the inspiratory muscles are in motion (index of the breathing frequency); and mean inspiratory flow $\left(\mathrm{V}_{\mathrm{T}} / \mathrm{T}_{\mathrm{I}}\right)$, which corresponds to an intensity index of the inspiratory drive..$^{25}$

$\mathrm{P}_{0.1}$ was expressed both in absolute value $\left(\mathrm{cm} \mathrm{H}_{2} \mathrm{O}\right)$ and as a percentage of maximal inspiratory pressure $\left(\mathrm{P}_{0.1} / \mathrm{P}_{\text {Imax }}\right.$ $\%)$ to normalize $\mathrm{P}_{0.1}$ for the individual differences in inspiratory muscle strength. ${ }^{26}$ The ratio of $\mathrm{P}_{0.1} / \mathrm{P}_{\text {Imax }}$ served as a substitute for respiratory capacity, whereby a higher $\mathrm{P}_{0.1} / \mathrm{P}_{\text {Imax }}$ ratio (ie, higher central respiratory drive and/or 
lower global inspiratory muscle strength) indicates reduced respiratory capacity. ${ }^{27}$

$\mathrm{T}_{\mathrm{T} 0.1}$ was estimated as $\left(\mathrm{P}_{0.1} / \mathrm{P}_{\text {Imax }} \times \mathrm{T}_{\mathrm{I}} / \mathrm{T}_{\text {tot }}\right)$. For the $\mathrm{T}_{\mathrm{T} 0.1}$ equation, $\mathrm{P}_{0.1}, \mathrm{P}_{\text {Imax }}$, and $\mathrm{T}_{\mathrm{I}} / \mathrm{T}_{\text {tot }}$ were assessed at rest and during exercise. $\mathrm{T}_{\mathrm{T} 0.1}$ is an index of the activity of overall inspiratory muscles. High values of $\mathrm{T}_{\mathrm{T} 0.1}$ correspond to high risk of fatigue, as shown by Hayot et al. ${ }^{13}$

\section{Cardiopulmonary Exercise Testing}

After subjects completed the spirometry test, they underwent tests with pressure measurements. Testing began with the subjects seated on the cycle ergometer while baseline measurements were made. The subjects breathed through the apparatus, which was connected to a breath-by-breath analyzer (CPX/D system, Medical Graphics Corporation). The total dead space of the breathing apparatus (valve and pneumotachograph) was $120 \mathrm{~mL}$; this value was entered into the software system for corrected calculation.

After 3 min of baseline measurements, the subjects performed an incremental exercise. The individualized exercise test protocol used in our laboratory usually results in an oxygen uptake $\left(\dot{\mathrm{V}}_{\mathrm{O}_{2}}\right.$ peak) test duration of 8-12 min, which meets the classical exercise testing recommendations. ${ }^{28}$ We chose 60 -s steps to perform 3 occlusion measurements in the last $30 \mathrm{~s} .{ }^{29}$

All subjects were encouraged to exercise until they felt too exhausted to continue. The exercise was considered maximal when 3 of the following criteria were met $^{30,31}$ : (1) leveling off $\dot{\mathrm{O}}_{\mathrm{O}_{2}}$; (2) maximal heart rate $\geq 90 \%$ theoretical heart rate maximum ${ }^{32}$; (3) respiratory exchange ratio $>1.15$; (4) pedal rate $<50 \mathrm{rpm}$; (5) volitional exhaustion. Peak $\dot{\mathrm{V}}_{\mathrm{O}_{2}}$ was defined as the highest $\dot{\mathrm{V}}_{\mathrm{O}_{2}}$ that could be sustained for at least $30 \mathrm{~s}$ during the last stage of exercise. At the end of the test, each subject was given a 2-min active recovery and a 3 -min passive recovery. $\mathrm{P}_{\text {Imax }}$ measurements were performed in the sitting position after the exercise test. Maneuvers were made until 3 technically satisfactory and reproducible measurements were obtained (variation $<10 \%)$. ${ }^{33}$ The highest score was kept for analysis.

Gas exchange measurements, breathing pattern, and $\mathrm{P}_{0.1}$ were measured during the last $30 \mathrm{~s}$ of each increment. ${ }^{29}$ Electrocardiography was monitored continuously during exercise testing through the use of a 12-lead electrocardiograph, and blood pressure was monitored with the use of an automated system. The modified Borg scale (0-10) was recorded to rate intensity of dyspnea at each increment (ie, breathing discomfort). ${ }^{34}$

Measurements of oxygen uptake $\left(\dot{\mathrm{V}}_{\mathrm{O}_{2}}\right)$ and carbon dioxide production $\left(\dot{\mathrm{V}}_{\mathrm{CO}_{2}}\right)$ were made using a computerized custom gas exchange. Ventilatory threshold was determined as described previously. ${ }^{35}$ Three validated methods were used concurrently to distinguish between ventilatory threshold and incremental exercise test data: (1) ventila- tory equivalent method ( $\dot{\mathrm{V}}_{\mathrm{E}} / \dot{\mathrm{V}}_{\mathrm{O}_{2}}$ method) ${ }^{36}$ (2) excess carbon dioxide method $\left(\mathrm{P}_{\mathrm{ETCO}_{2}}\right),{ }^{36}$ and (3) modified V-slope method. ${ }^{37}$ This point was measured in a double blind design, according to the best agreement between 2 independent observers. In case of disagreement (ie, $>10 \%$ difference between the 2 observers), a third investigator was asked to assess the thresholds. The value retained was the average of the values in closer agreement. Electrocardiography and pulse oximetry were carried out continuously, and blood pressure was taken by auscultation at rest, at the end of each stage of exercise, at peak exercise, and during recovery from exercise.

\section{Aerobic Exercise Training}

All subjects were ambulatory and were trained in-hospital at a cardiovascular rehabilitation service. Subjects were asked to perform one session of training/d, 5 times/week, for 8 weeks, to complete a total of 40 sessions. Subjects exercised on an electromagnetically braked cycle ergometer (Ergoline 800, CareFusion, San Diego, California), at a cadence of 60 rpm, and exercise intensity was monitored by heart rate using a Sport Tester PE3000 (Polar Electro, Kemple, Finland). Each session included a 5-min period of warm-up with no resistance, followed by a period exercising at the target heart rate corresponding to the ventilatory threshold $^{38-40}$ determined on the cardiopulmonary exercise test. During the first 2 weeks, the duration of the exercise at the target intensity was $30 \mathrm{~min}$, plus 5 min every 2 weeks until the exercise reached $45 \mathrm{~min}$. The exercise sessions ended with a 5-min cool-down period without resistance. The heart rate monitor was set so that subjects would exercise within 5 beats/min of the prescribed intensity. An alarm rang to remind subjects to train within the preselected range. To ensure that training procedures were properly followed, a cardiologist and an instructor supervised each session.

\section{Statistical Analysis}

Descriptive statistics were used to describe the sample. The values are reported as mean $\pm \mathrm{SD}$. Statistical comparisons were performed using StatView software (Abacus Concepts, Berkeley, California). For each outcome measure, the normality of the data was investigated with the Shapiro-Wilk test. Paired $t$ tests for normally distributed data and Wilcoxon signed-rank tests for non-normally distributed data were used to compare pre- and postaerobic exercise variables. Exercise data were compared at the same work load (40,60, 80, 100, 120, and 140 watts), using a 2-way analysis of the variance for repeated measures or the Friedman test when the normality test of the distribution failed. When the analysis of variance $F$ ratio was significant, the post hoc Bonferroni test was used to 
Table 1. Anthropometric and Spirometric Parameters and Maximal Inspiratory Pressure at Rest in Subjects With Obesity Before and After Exercise Training

\begin{tabular}{lccc}
\hline \hline \multicolumn{1}{c}{ Parameters } & $\begin{array}{c}\text { Before } \\
\text { Training }\end{array}$ & $\begin{array}{c}\text { After } \\
\text { Training }\end{array}$ & $P$ \\
\hline Weight, kg & $120 \pm 16$ & $112 \pm 15$ & .05 \\
${\text { BMI, } \mathrm{kg} / \mathrm{m}^{2}}$ & $41 \pm 6$ & $39 \pm 7$ & .62 \\
$\mathrm{FEV}_{1}, \%$ predicted & $95 \pm 18$ & $97 \pm 14$ & .86 \\
$\mathrm{FVC}, \%$ predicted & $95 \pm 17$ & $94 \pm 12$ & .91 \\
$\mathrm{FEV}, / \mathrm{FVC}, \%$ predicted & $85 \pm 9$ & $87 \pm 13$ & .81 \\
$\mathrm{PEF}, \%$ predicted & $102 \pm 15$ & $105 \pm 9$ & .74 \\
$\mathrm{P}_{\text {Imax }}$, cm $\mathrm{H}_{2} \mathrm{O}$ & $75 \pm 12$ & $82 \pm 10$ & .05 \\
& & & \\
\hline Results are mean \pm SD. & & & \\
BMI $=$ body mass index & & & \\
PEF $=$ peak expiratory flow & & & \\
$\mathrm{P}_{\text {Imax }}=$ maximal inspiratory pressure & & & \\
\hline
\end{tabular}

perform pairwise multiple comparisons. Differences were considered significant for $P<.05$.

Statistical analysis was completed with the estimation of effect size indices, which evaluate the magnitude of aerobic exercise effect at rest and at maximal exercise. The formula Cohen's dz was used (mean change score divided by the SD of change), because this is the effect size index recommended for matched pairs. ${ }^{41}$ Cohen's $\mathrm{dz}$ for each outcome measure was calculated using the G*Power 3 software (University of Düsseldorf, Düsseldorf, Germany), and effect sizes were expressed as small $(\geq 0.2)$, medium $(\geq 0.5)$, or large $(\geq 0.8) .{ }^{42}$ Effect size and power analysis was conducted, and we estimated that a sample size of 19 subjects would have a power of $80 \%$ to detect significant enhancement in cardiorespiratory and inspiratory muscle performance at rest and at maximal exercise.

\section{Results}

\section{Spirometry}

There was no significant difference in the predictive values: percent-of-predicted FEV, percent-of-predicted FVC, percent-of-predicted FEV/FVC, and percent-of-predicted peak expiratory flow (Table 1) before and after training.

\section{Gas Exchange and Cardiorespiratory Parameters}

At rest condition, there was no significant difference before and after training for the following parameters: $\dot{\mathrm{V}}_{\mathrm{E}}$, $\mathrm{V}_{\mathrm{T}}$, f, $\dot{\mathrm{V}}_{\mathrm{O}_{2}}$, and $\dot{\mathrm{V}}_{\mathrm{CO}_{2}}$. At maximal exercise, $\dot{\mathrm{V}}_{\mathrm{E}}$ and $\mathrm{V}_{\mathrm{T}}$ are not statistically different between pre- and post-training, however, Power output $(P=.048$, effect size $=0.79), \dot{\mathrm{V}}_{\mathrm{O}_{2}}$ peak $(P=.02$, effect size $=0.92)$, and $\dot{\mathrm{V}}_{\mathrm{CO}_{2}}(P=.02$, effect size $=0.92)$, f $(P=.049$, effect size $=.97)$, and $\mathrm{V}_{\mathrm{T}}(P=.037$, effect size $=1.51)$ were significantly higher after exercise training (Table 2). At submaximal exercise, $\dot{V}_{E}$ was significantly lower after exercise training (Fig. 1).

\section{Respiratory Muscle Parameters}

At rest, the $\mathrm{P}_{\text {Imax }}$ is significantly higher after exercise training $(P=.049$, effect size $=0.62)$, and $\mathrm{P}_{0.1}$ is significantly lower after exercise training (Table 1 ). There is no difference in pressure, $\mathrm{P}_{0.1} / \mathrm{P}_{\text {Imax }}, \mathrm{T}_{\mathrm{I}} / \mathrm{T}_{\text {tot }}$, and the $\mathrm{T}_{\mathrm{T} 0.1}$ after training $(P=.049$, effect size $=1.016)($ Table 3$)$. For the same work load, the values of the occlusion pressure $\left(\mathrm{P}_{0.1}\right)$ (Fig. 2) $\left(\mathrm{P}_{0.1} / \mathrm{P}_{\text {Imax }}\right)$ (Fig. 3) and $\mathrm{T}_{\mathrm{T} 0.1}$ (Fig. 5) are significantly lower after training, but at maximal exercise, there is no difference (Table 3).

At rest, maximal and submaximal exercise, no significant difference in $\mathrm{T}_{\mathrm{I}} / \mathrm{T}_{\text {tot }}$ before and after exercise training was observed (Table 3 and Fig. 4). For the same work load, $\mathrm{T}_{\mathrm{T} 0.1}$ (Fig. 5) and dyspnea scores (Fig. 6) are significantly lower after exercise training, but at maximal exercise, this difference is not statistically different (Tables 2 and 3).

\section{Discussion}

To our knowledge, no study has investigated effect of exercise training at ventilatory threshold on inspiratory muscle performance in obese subjects. The main finding of the present study is that exercise training improves exercise capacity, ventilatory efficiency, inspiratory muscle performance, and dyspnea. The present study has an adequate sample size $(n=19)$ and high study power $(80 \%)$ to support our hypothesis.

Pulmonary function tests provide an indirect and nonspecific examination of respiratory muscle function. ${ }^{19}$ The absence of changes in pulmonary function with exercise training is in agreement with other studies in older obese adults ${ }^{43,44}$ and subjects with lung disease. ${ }^{45}$ However, Lorenzo et $\mathrm{al}^{46}$ have demonstrated that highly fit, obese athletes showed an increased peak expiratory flow, which partly explains the high cardiorespiratory fitness and exercise capacity in these athletes. Thus, peak expiratory flow may be an early adaptation that occurs with exercise training. The impact of various methods of weight loss on pulmonary function was examined in several previous studies. In morbidly obese subjects, gastroplasty improved residual volume, total lung capacity, FRC, FEV ${ }_{1}$, and FVC. . $^{4,47}$ Conversely, weight gain results in a decline in $\mathrm{FEV}_{1}$ and FVC. ${ }^{48}$ Our inability to detect differences in pulmonary function test parameters may be due to a lower magnitude of weight loss compared with the average $34.2-\mathrm{kg}$ loss after gastroplasty reported by Thomas et al. ${ }^{47}$ Therefore, magnitude of weight loss may account for the lack of change in dynamic pulmonary function in the present study. 
Table 2. Gas Exchanges and Cardiorespiratory Parameters at Rest and With Maximal Exercise, Before and After Exercise Training in Obese Subjects

\begin{tabular}{|c|c|c|c|c|c|c|}
\hline \multirow{2}{*}{ Parameters } & \multicolumn{2}{|c|}{ Rest } & \multirow[b]{2}{*}{$P$} & \multicolumn{2}{|c|}{ Maximal Exercise } & \multirow[b]{2}{*}{$P$} \\
\hline & Before Training & After Training & & Before Training & After Training & \\
\hline Power output, watts & 0 & 0 & & $162 \pm 25$ & $184 \pm 30$ & .05 \\
\hline$\dot{\mathrm{V}}_{\mathrm{O}_{2}}$ peak, $\mathrm{mL} / \mathrm{kg} / \mathrm{min}$ & $3.01 \pm 0.68$ & $2.9 \pm 0.73$ & .83 & $20.3 \pm 3.21$ & $24.5 \pm 5.1$ & .02 \\
\hline$\dot{\mathrm{V}}_{\mathrm{O}_{2}}$ peak, $\mathrm{mL} / \mathrm{min}$ & $475 \pm 80$ & $425 \pm 94$ & .21 & $2568 \pm 355$ & $2857 \pm 500$ & .05 \\
\hline$\dot{\mathrm{V}}_{\mathrm{CO}_{2}}, \mathrm{~mL} / \mathrm{min}$ & $397 \pm 88$ & $363 \pm 54$ & .77 & $3000 \pm 386$ & $3354 \pm 380$ & .02 \\
\hline RER & $0.83 \pm 0.07$ & $0.8 \pm 0.08$ & .46 & $1.2 \pm 0.1$ & $1.3 \pm 0.15$ & .06 \\
\hline$\dot{\mathrm{V}}_{\mathrm{E}}, \mathrm{L} / \mathrm{min}$ & $12.1 \pm 2.8$ & $10.8 \pm 2.4$ & .31 & $88 \pm 14$ & $90.5 \pm 14.9$ & .04 \\
\hline $\mathrm{V}_{\mathrm{T}}, \mathrm{L}$ & $0.560 \pm 0.24$ & $0.67 \pm 0.17$ & .41 & $1.87 \pm 0.32$ & $2.3 \pm 0.22$ & .01 \\
\hline $\mathrm{f}$, breaths/min & $22 \pm 4$ & $18 \pm 5$ & .06 & $45 \pm 6$ & $38 \pm 8$ & .01 \\
\hline RPB (0-10) & 0 & 0 & & $7.2 \pm 2.55$ & $6.8 \pm 2.3$ & .06 \\
\hline $\begin{array}{l}\text { Results are mean } \pm \mathrm{SD} \\
\dot{\mathrm{V}}_{\mathrm{O}_{2}}=\text { oxygen uptake } \\
\dot{\mathrm{V}}_{\mathrm{CO}_{2}}=\text { carbon dioxide output } \\
\dot{\mathrm{V}}_{\mathrm{E}}=\text { minute ventilation } \\
\mathrm{RER}=\text { rate of exchange ratio } \\
\mathrm{V}_{\mathrm{T}}=\text { tidal volume } \\
\mathrm{f}=\text { breathing frequency } \\
\mathrm{RPB}=\text { rating of perceived bre }\end{array}$ & & & & & & \\
\hline
\end{tabular}

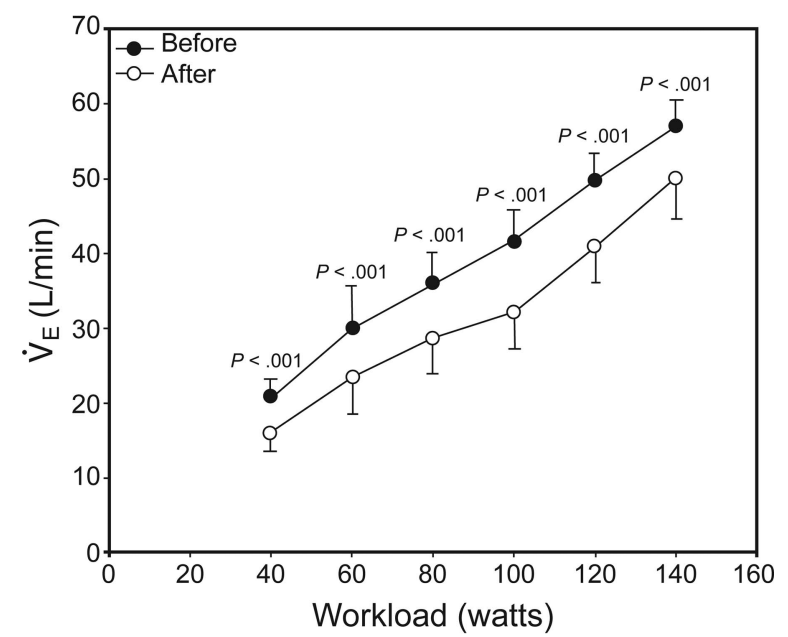

Fig. 1. Minute ventilation $\left(\dot{V}_{\mathrm{E}}\right)$ at comparable work loads $(40,60$, $80,100,120$, and 140 watts) before and after exercise training in obese subjects. The circles represent the work loads reached by all subjects before and after training.

$\dot{\mathrm{V}}_{\mathrm{O}_{2}}$ peak and peak power output best measure cardiorespiratory fitness, and exercise capacity ${ }^{2}$ increases after exercise training, which is consistent with other studies. ${ }^{14}$ An increase in $\dot{\mathrm{V}}_{\mathrm{O}_{2}}$ peak could be explained by structural changes in skeletal muscle. Indeed, exercise training may increase blood flow to active muscles, improving peripheral oxygen extraction and partially reversing the abnormalities of skeletal muscles in obese patients. ${ }^{49}$ Improvement in cycle exercise performance after training was explained by improved efficiency (ie, reduced slopes of $\mathrm{CO}_{2}$ and $\mathrm{O}_{2}$ over time), ${ }^{50}$ reduced ventilation, and improved oxidative capacity. Thus, the present study sug- gested that aerobic exercise training at ventilator threshold might improve exercise tolerance, probably associated with an improvement in ventilation requirements during exercise. These observations are supported by the finding that dyspnea scores were significantly lower after exercise training. This can be an additional explanation for the better $\dot{\mathrm{V}}_{\mathrm{O}_{2}}$ peak and maximal aerobic power.

Exercise training, for the same work load, generates a significant reduction in minute ventilation. ${ }^{51} \dot{\mathrm{V}}_{\mathrm{E}}$ was lower due to the increased $\dot{V}_{\mathrm{O}_{2}}$ peak and enhanced cardiac function. ${ }^{9}$ Obese patients maintain a lower minute ventilation after training, following a respiratory strategy characterized by an increase in the tidal volume and a lower breathing frequency. Change of breathing pattern has 2 major advantages: (1) the ratio of dead space to tidal volume decreases, which leads to an increase in effective alveolar ventilation, inducing improvement of ventilation/perfusion ${ }^{52}$; (2) it diminishes the work of breathing, exertional dyspnea, and energy costs of breathing. ${ }^{9}$ This strategy optimizes the work of breathing, limiting further increase in the elastic work of breathing at high lung volumes, which indicates that respiratory muscle fatigue leading to a rapid, shallow breathing pattern is delayed. Obese patients may be less hyperinflated at a given work rate after training, although we cannot confirm this because we did not assess changes in lung volume during exercise. Dynamic hyperinflation compromises the ability of the inspiratory muscles to generate pressure; thus, functional inspiratory muscle weakness develops. ${ }^{53}$ Decreased hyperinflation might be explained by increased respiratory muscle endurance. Inspiratory muscle fatigue is known to cause rapid, shallow breathing ${ }^{3}$; tidal volume is less for a given level of 
Ventilatory Efficiency After Endurance Exercise

Table 3. Respiratory Muscle Performance Parameters at Rest and With Maximal Exercise, Before and After Exercise Training in Subjects With Obesity

\begin{tabular}{|c|c|c|c|c|c|c|}
\hline \multirow{2}{*}{ Parameters } & \multicolumn{2}{|c|}{ Rest } & \multirow[b]{2}{*}{$P$} & \multicolumn{2}{|c|}{ Maximal Exercise } & \multirow[b]{2}{*}{$P$} \\
\hline & Before Training & After Training & & Before Training & After Training & \\
\hline $\mathrm{P}_{0.1}, \mathrm{~cm} \mathrm{H}_{2} \mathrm{O}$ & $2.5 \pm 0.29$ & $2.2 \pm 0.30$ & .01 & $18.6 \pm 3.81$ & $20.82 \pm 2.9$ & .13 \\
\hline $\mathrm{P}_{0.1} / \mathrm{P}_{\operatorname{Imax}}$ & $0.038 \pm 0.007$ & $0.035 \pm 0.004$ & .05 & $0.37 \pm 0.04$ & $0.35 \pm 0.05$ & .39 \\
\hline $\mathrm{T}_{\mathrm{I}} / \mathrm{T}_{\text {tot }}$ & $0.42 \pm 0.05$ & $0.40 \pm 0.07$ & .59 & $0.5 \pm 0.042$ & $0.49 \pm 0.028$ & .68 \\
\hline $\mathrm{T}_{\mathrm{T} 0.1}$ & $0.017 \pm 0.003$ & $0.012 \pm 0.004$ & .01 & $0.222 \pm 0.021$ & $0.210 \pm 0.03$ & .37 \\
\hline \multicolumn{7}{|c|}{$\begin{array}{l}\text { Results are mean } \pm \mathrm{S} D \\
\mathrm{P}_{0.1}=\text { mouth occlusion pressure } \\
\mathrm{P}_{0.1} / \mathrm{P}_{\text {Imax }}=\text { mouth occlusion pressure to maximal inspiratory pressure } \\
\mathrm{T}_{1} / \mathrm{T}_{\text {tot }}=\text { duty cycle } \\
\mathrm{T}_{\mathrm{T} 0.1}=\text { tension time index of inspiratory muscle }\end{array}$} \\
\hline
\end{tabular}

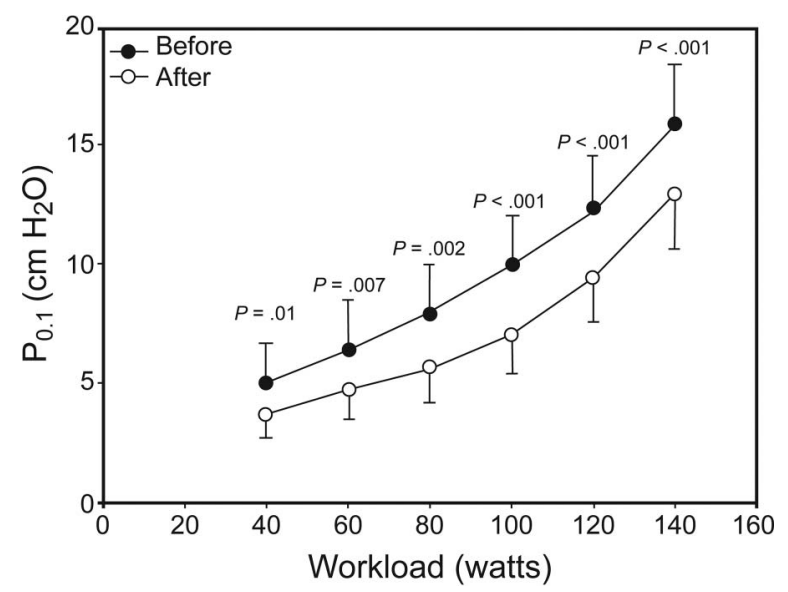

Fig. 2. Mouth occlusion pressure $\left(\mathrm{P}_{0.1}\right)$ at comparable work loads $(40,60,80,100,120$, and 140 watts) before and after exercise training in obese subjects. The circles represent the work loads reached by all subjects before and after training.

$\dot{\mathrm{V}}_{\mathrm{E}}$ in the fatigued than in the unfatigued state. If the inspiratory muscles are stronger after training, decreased fatigue might lead to less hyperinflation. ${ }^{45}$

Reductions in ventilation following training in obese patients would be likely to have a salutary effect on dyspnea because of reduced central motor command output from the respiratory center. As the velocity of respiratory muscle contraction increases (eg, increased breathing frequency), the capacity to generate tension decreases. Improvements in exercise capacity can, in part, be explained by improved respiratory muscle function.

The $\mathrm{P}_{\text {Imax }}$ generated during a Müller maneuver reflects ventilatory capacity, the development of respiratory insufficiency, and inspiratory muscle weakness. ${ }^{12,33}$ Our findings have demonstrated that 8 weeks of endurance training at ventilatory threshold increases inspiratory muscle strength. To our knowledge, no studies have directly assessed the effects of endurance training on respiratory muscle strength in obese subjects. Improvements in $\mathrm{P}_{\text {Imax }}$ ob-

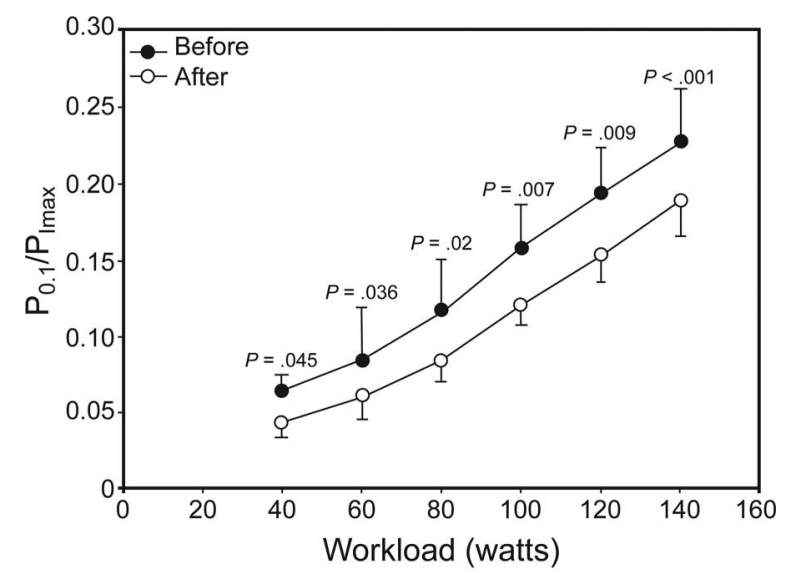

Fig. 3. Ratio of occlusion pressure to maximal inspiratory pressure $\left(\mathrm{P}_{0.1} / \mathrm{P}_{\text {Imax }}\right)$ at comparable work loads $(40,60,80,100,120$, and 140 watts) before and after exercise training in obese subjects. The circles represent the work loads reached by all subjects before and after training.

served in our study are similar to improvements identified after specific respiratory muscle training. ${ }^{54}$ The training of the respiratory muscles applied to healthy and pathological subjects increases $\mathrm{P}_{\text {Imax }}$, associated with a decrease in shortness of breath ${ }^{55}$ in healthy and pathological subjects with chronic obstructive pulmonary disease ${ }^{56}$. The increase in maximal inspiratory muscle pressure after endurance training may be the result of the same mechanisms observed in the lower limbs. Thus, aerobic training helps improve blood perfusion of the respiratory muscles. ${ }^{57}$ The increase in blood perfusion, following endurance training, is the result of an increase in capillarization, mitochondrial density, ${ }^{58}$ activities of oxidative enzymes, and reverse metabolic and histological abnormalities of respiratory muscles. ${ }^{57}$ The improvement in $\mathrm{P}_{\text {Imax }}$ is strongly related to a combination of 3 factors: weight, waist circumference, and nutrition. ${ }^{59}$ In our study, endurance training resulted in weight loss, which could explain the increase in $\mathrm{P}_{\text {Imax }}$. Our results were in accordance with a previous study. ${ }^{60}$ The predominant 


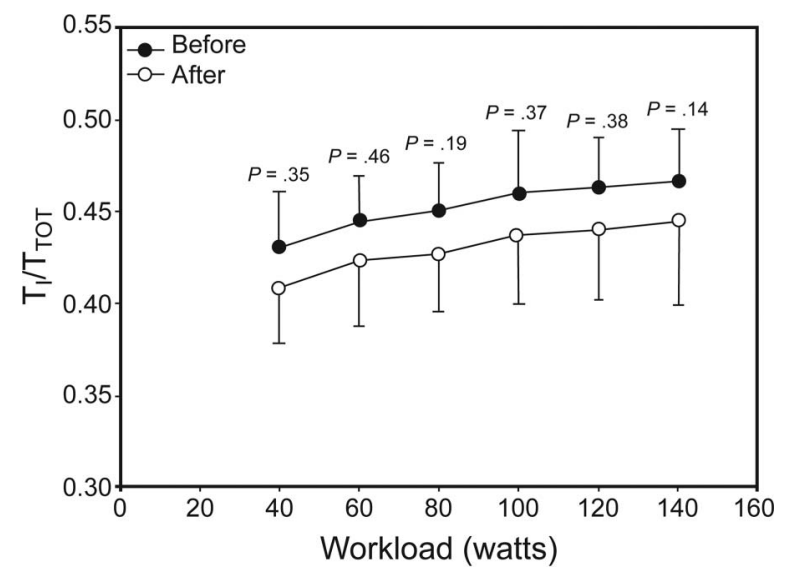

Fig. 4. Duty cycle $\left(T_{1} / T_{\text {tot }}\right)$ at comparable work loads $(40,60,80$, 100,120 , and 140 watts) before and after exercise training in obese subjects. The circles represent the work loads reached by all subjects before and after training.

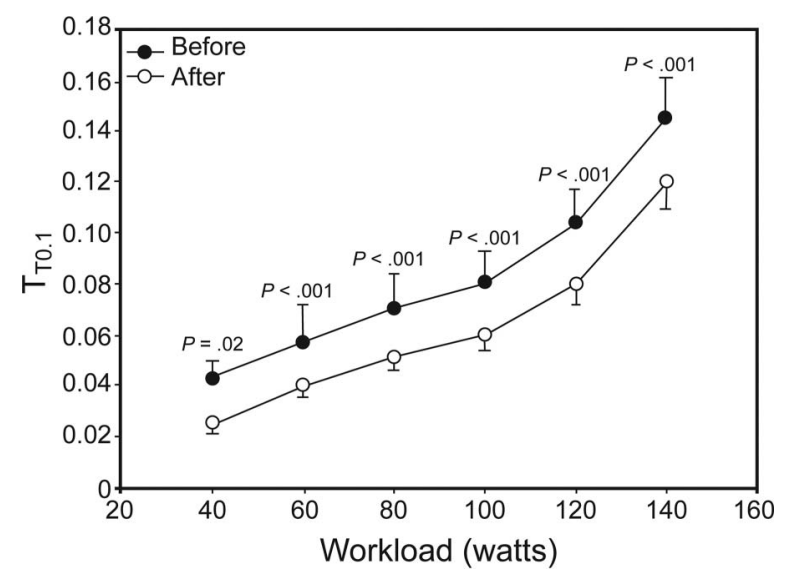

Fig. 5. Tension-time index of the inspiratory muscles $\left(\mathrm{T}_{\mathrm{T0.1}}\right)$ at comparable work loads $(40,60,80,100,120$, and 140 watts) before and after exercise training in patients with obesity. The circles represent the work loads reached by all subjects before and after training.

change was improvement in $\mathrm{P}_{\text {Imax }}$. The improvement in respiratory muscle performance correlated with weight loss. Thus, when inspiratory muscles generate sufficient tension, the respiratory system detects this improvement and decreases the central ventilatory drive.

Respiratory muscle function can be evaluated by measurement of $\mathrm{T}_{\mathrm{T} 0.1}$, the noninvasive tension-time index of the inspiratory muscles. ${ }^{13}$ To our knowledge, no data exist in the literature relating the effect of aerobic exercise training on respiratory muscle function assessed by measurement of $\mathrm{T}_{\mathrm{T} 0.1}$ in obese subjects. At the same work load of submaximal exercise, $\mathrm{T}_{\mathrm{T} 0.1}$ was significantly lower after training, indicating higher efficiency and improvement in respiratory muscle performance. Decrease in $\mathrm{T}_{\mathrm{T} 0.1}$ is mainly due to a decrease in pressure parameters $\left(\mathrm{P}_{0.1}\right.$ and $\left.\mathrm{P}_{0.1} / \mathrm{P}_{\text {Imax }}\right)$, since $T_{I} / T_{\text {tot }}$ is unchanged after training. Our results were

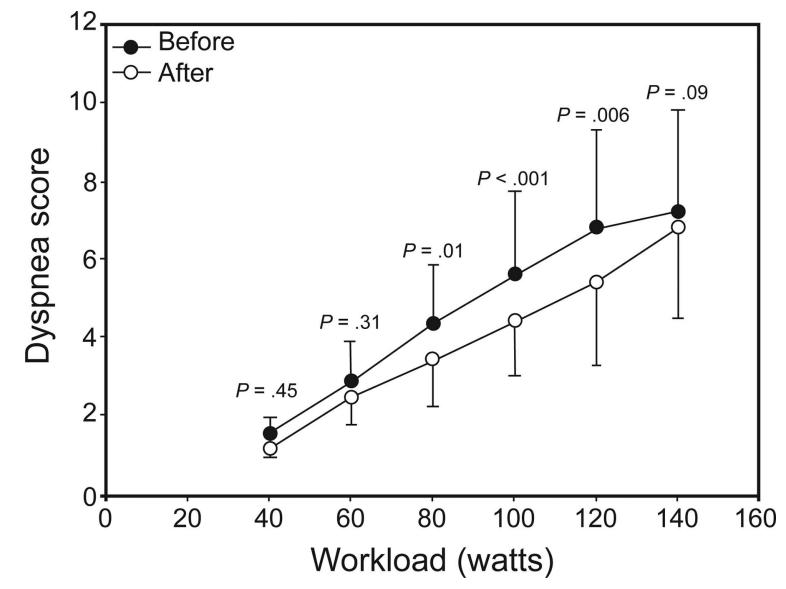

Fig. 6. Dyspnea score at comparable work loads (40, 60, 80, 100 , 120 , and 140 watts) before and after exercise training in obese subjects. The circles represent the work loads reached by all subjects before and after training.

similar to those of Bhammar et al, ${ }^{61}$ where moderate weight loss induced significant improvements in respiratory function at rest and during submaximal exercise in otherwise healthy subjects with obesity. These changes in breathing load could have positive effects on exercise endurance and adherence to physical activity.

$\mathrm{P}_{0.1}$ is an estimate of the neuromuscular drive to breathe, because it is measured at zero flow and is thus independent of respiratory system compliance and resistance. ${ }^{62} \mathrm{P}_{0.1}$ was significantly reduced after exercise training to the same work load, and the decrease of $P_{0.1}$ is correlated with increased $\mathrm{P}_{\text {Imax }} \cdot 3,8,63$

Absolute values of $\mathrm{P}_{0.1}$ might underestimate the effective neural drive in patients with inspiratory muscle weakness. ${ }^{12} \mathrm{P}_{0.1} / \mathrm{P}_{\text {Imax }}$ ratio reflects a balance between the magnitude of the respiratory load and the muscle strength available to meet the load. ${ }^{27} \mathrm{P}_{0.1} / \mathrm{P}_{\text {Imax }}$ was significantly lower after exercise training describing lower inspiratory muscle energy demands. Reduction of $\mathrm{P}_{0.1} / \mathrm{P}_{\text {Imax }}$ ratio as a consequence of exercise training (ie, lower central respiratory drive and/or higher global inspiratory muscle strength) indicates increased respiratory capacity. ${ }^{27}$

The lower inspiratory demand (in relation to the inspiratory reserve) explains the lower $\mathrm{T}_{\mathrm{T} 0.1}$ in obese subjects. Our result indicates enhanced efficiency of the inspiratory muscles, which may then lead to lower energy demand for the same work load and thus to a lower risk of inspiratory muscle weakness, which may lead to improved exercise performance.

In our study, the decrease in minute ventilation increased the expiration time out of proportion to the $\mathrm{T}_{\mathrm{I}}$, thereby decreasing the duty cycle $\mathrm{T}_{\mathrm{I}} / \mathrm{T}_{\text {tot }}$ and $\mathrm{T}_{\mathrm{T} 0.1}{ }^{3}$. Fractional duty cycle determines the stress placed on the respiratory muscles. ${ }^{64}$ However, a reduction in $\mathrm{T}_{\mathrm{I}} / \mathrm{T}_{\text {tot }}$ is a useful strategy for decreasing the risk of muscle fatigue. Obese sub- 
jects rarely show a meaningful change in this index in clinical practice. ${ }^{65}$ The muscle contraction duty cycle (time under tension/total contraction time) directly impacts blood flows, such that with high duty cycles (longer time under tension relative to total contraction time), blood flow to the active skeletal muscle becomes limited, ${ }^{66}$ whereas the blood flow is not compromised at low duty cycles (shorter time under tension relative to total contraction time) even with increased contraction frequencies. ${ }^{67}$

Although, at a given $\dot{\mathrm{V}}_{\mathrm{E}}$, a shorter $\mathrm{T}_{\mathrm{I}} / \mathrm{T}_{\text {tot }}$ converted into a greater inspiratory flow, the inspiratory muscles need to generate more pressure during inspiration. However, they contract for a shorter fraction of cycle time, which tends to reduce the $\mathrm{T}_{\mathrm{T} 0.1}{ }^{64}$ and this approach might result in less breathlessness. Obese subjects with the lowest duty cycle (the ratio of inspiratory time to breath duration) tend to have the higher inspiratory muscle performance 3,64 and a lower amount of inspiratory muscle work. ${ }^{68}$

The $\mathrm{T}_{\mathrm{T} 0.1}$ of inspiratory muscle is a very good mechanical index of $\mathrm{O}_{2}$ consumption of the respiratory muscles, respiratory $\dot{\mathrm{O}}_{\mathrm{O}_{2}}$, over a wide variety of breathing patterns. ${ }^{69}$ The improvement of inspiratory muscle performance depending on muscle strength is visible by the examination of the $\mathrm{T}_{\mathrm{T} 0.1}$. Thus, increasing $\mathrm{P}_{\text {Imax }}$ might increase ventilatory endurance as well as endurance for inspiratory loads. Our study defined the interrelationships between change in Borg scale and inspiratory effort as previously. 3,8,63 Aerobic exercise training may decrease breathlessness, by reducing the $\mathrm{T}_{\mathrm{T} 0.1}$ of the inspiratory muscles and oxygen cost of breathing. 69

One of the mechanisms of dyspnea in obese patients could be related to inspiratory muscle dysfunction. ${ }^{11}$ This symptom appears when the activity of these muscles is increased and/or when these muscles are weak. ${ }^{70}$ Dyspnea intensity at the same work load was lower after exercise training. The lower dyspnea intensity in the obese subjects is probably the result of improved ventilatory mechanics. ${ }^{71}$ Significant decreases in dyspnea with only moderate weight loss is very encouraging for obese individuals who suffer from breathlessness when exercising. Dyspnea can be reduced in obese patients by exercise training, with concomitant improvements in both exercise capacity and inspiratory muscle function. This attenuation of dyspnea is concomitant with decreased ventilation and increased inspiratory muscle performance (decreased $\mathrm{T}_{\mathrm{T} 0.1}$ ). The reduction of dyspnea is linked to the improved performance of the inspiratory muscles characterized by an increase in the force generated by the inspiratory muscles $\left(\mathrm{P}_{\mathrm{Imax}}\right)$ and decreased $\dot{\mathrm{V}}_{\mathrm{E}}$, breathing frequency and $\mathrm{T}_{\mathrm{I}} / \mathrm{T}_{\text {tot }}{ }^{72}$

Our results suggest that aerobic exercise and moderate weight loss could reduce the breathing load during exercise and improve inspiratory muscle performance, ${ }^{61}$ which could have a positive effect on breathing pattern, ${ }^{73}$ respiratory function, ${ }^{61}$ maximal inspiratory pressure, ${ }^{60}$ breath- ing mechanics during submaximal exercise, ${ }^{74}$ breathlessness on exertion, ${ }^{75}$ and exercise tolerance, although this requires further study.

The present study has certain limitations. The maximal inspiratory pressure test is volitional and requires full cooperation. Accordingly, an apparently low result may sometimes be due to a lack of motivation and does not necessarily indicate reduced inspiratory or expiratory muscle strength. We recommend using the sniff test or phrenic nerve stimulation in future work in this area.

\section{Conclusions}

The main finding of this study was that endurance training is beneficial, since it results in less energy demand $\left(\mathrm{P}_{0.1} / \mathrm{P}_{\text {Imax }}\right)$ and an increase in inspiratory muscle efficiency, which leads to a decrease in $\mathrm{T}_{\mathrm{T} 0.1}$ and improved exercise tolerance.

\section{ACKNOWLEDGMENTS}

We thank the medical staff of the Department of Cardiac Rehabilitation of Corbie Hospital for technical assistance and the obese subjects from the Nutritional and Physical Rehabilitation Department of Corbie Hospital (France) for dedication to the study.

\section{REFERENCES}

1. Babb TG. Mechanical ventilatory constraints in aging, lung disease, and obesity: perspectives and brief review. Med Sci Sports Exerc 1999;31(1 Suppl):S12-S22.

2. Babb TG. Obesity: challenges to ventilatory control during exercise: a brief review. Respir Physiol Neurobiol 2013;189(2):364-370.

3. Chlif M, Keochkerian D, Feki Y, Vaidie A, Choquet D, Ahmaidi S. Inspiratory muscle activity during incremental exercise in obese men. Int J Obes 2007;31(9):1456-1463.

4. Littleton SW. Impact of obesity on respiratory function. Respirology 2012;17(1):43-49.

5. Lin CK, Lin CC. Work of breathing and respiratory drive in obesity. Respirology 2012;17(3):402-411.

6. Kaufman C, Kelly AS, Kaiser DR, Steinberger J, Dengel DR. Aerobic-exercise training improves ventilatory efficiency in overweight children. Pediatr Exerc Sci 2007;19(1):82-92.

7. Prado DM, Silva AG, Trombetta IC, Ribeiro MM, Nicolau CM, Guazzelli IC, et al. Weight loss associated with exercise training restores ventilatory efficiency in obese children. Int J Sports Med 2009;30(11):821-826.

8. Chlif M, Keochkerian D, Mourlhon C, Choquet D, Ahmaidi S. Noninvasive assessment of the tension-time index of inspiratory muscles at rest in obese male subjects. Int J Obes 2005;29(12):1478-1483.

9. Mendelson M, Michallet AS, Estève F, Perrin C, Levy P, Wuyam B, Flore P. Ventilatory responses to exercise training in obese adolescents. Respir Physiol Neurobiol 2012;184(1):73-79.

10. Koenig SM. Pulmonary complications of obesity. Am J Med Sci 2001;321(4):249-279.

11. Whipp BJ, Davis JA. The ventilatory stress of exercise in obesity. Am Rev Respir Dis 1984;129(2 Pt 2):S90-S92.

12. American Thoracic Society/European Respiratory Society. Statement on respiratory muscle testing. Am J Respir Crit Care Med 2002; 166(4):518-624. 


\section{Ventilatory Efficiency After Endurance Exercise}

13. Hayot M, Ramonatxo M, Matecki S, Milic-Emili J, Prefaut C. Noninvasive assessment of inspiratory muscle function during exercise. Am J Respir Crit Care Med 2000;162(6):2201-2207.

14. Jones AM, Carter $\mathrm{H}$. The effect of endurance training on parameters of aerobic fitness. Sports Med 2000;29(6):373-386.

15. Geiger R, Willeit J, Rummel M, Högler W, Stübing K, Strasak A, et al. Six-minute walk distance in overweight children and adolescents: effects of a weight-reducing program. J Pediatr 2011;158(3): 447-451.

16. Redlich CA, Tarlo SM, Hankinson JL, Townsend MC, Eschenbacher WL, Von Essen SG, et al. Official American Thoracic Society technical standards: spirometry in the occupational setting. Am J Respir Crit Care Med 2014;189(8):983-993.

17. Johannessen A, Omenaas ER, Eide GE, Bakke PS, Gulsvik A. Feasible and simple exclusion criteria for pulmonary reference populations. Thorax 2007;62(9):792-798.

18. Laszlo G. Standardisation of lung function testing: helpful guidance from the ATS/ERS Task Force. Thorax 2006;61(9):744-746.

19. Miller MR, Hankinson J, Brusasco V, Burgos F, Casaburi R, Coates A, et al. Standardization of lung function testing: standardization of spirometry. Eur Respir J 2005;26(2):319-338.

20. Castellsagué J, Burgos F, Sunyer J, Barberà JA, Roca J. Prediction equations for forced spirometry from European origin populations. Barcelona Collaborative Group on Reference Values for Pulmonary Function Testing and the Spanish Group of the European Community Respiratory Health Survey. Respir Med 1998;92(3):401-407.

21. Whitelaw WA, Derenne JP, Milic-Emili J. Occlusion pressure as a measure of respiratory center output in conscious man. Respir Physiol 1975;23(2):181-199.

22. Kera T, Aihara A, Inomata T. Reliability of airway occlusion pressure as an index of respiratory motor output. Respir Care 2013;58(5): 845-849.

23. Hautmann H, Hefele S, Schotten K, Huber RM. Maximal inspiratory mouth pressures (PIMAX) in healthy subjects: what is the lower limit of normal? Respir Med 2000;94(7):689-693.

24. Black LF, Hyatt RE. Maximal respiratory pressures: normal values and relationship to age and sex. Am Rev Respir Dis 1969;99(5):696702 .

25. Neder JA, Dal Corso S, Malaguti C, Reis S, De Fuccio MB, Schmidt $\mathrm{H}$, et al. The pattern and timing of breathing during incremental exercise: a normative study. Eur Respir J 2003;21(3):530-538.

26. Roussos C, Koutsoukou A. Respiratory failure. Eur Respir J Suppl 2003;47:3s-14s.

27. Fernández R, Cabrera J, Calaf N, Benito S. P 0.1/PIMax: an index for assessing respiratory capacity in acute respiratory failure. Intensive Care Med 1990;16(3):175-179.

28. Wasserman K. Principles of exercise testing and interpretation: including pathophysiology and clinical applications. Philadelphia: Lippincott Williams \& Wilkins; 2005:145-177.

29. Prioux J, Ramonatxo M, Hayot M, Mucci P, Préfaut C. Effect of ageing on the ventilatory response and lactate kinetics during incremental exercise in man. Eur J Appl Physiol 2000;81(1-2):100-107.

30. Edvardsen E, Hem E, Anderssen SA. End criteria for reaching maximal oxygen uptake must be strict and adjusted to sex and age: a cross-sectional study. PLoS One 2014;9(1):e85276.

31. Poole DC, Wilkerson DP, Jones AM. Validity of criteria for establishing maximal $\mathrm{O}_{2}$ uptake during ramp exercise tests. Eur J Appl Physiol 2008;102(4):403-410.

32. Hansen JE, Sue DY, Wasserman K. Predicted values for clinical exercise testing. Am Rev Respir Dis 1984;129(2 Pt 2):S49-S55.

33. Harik-Khan RI, Wise RA, Fozard JL. Determinants of maximal inspiratory pressure. The Baltimore Longitudinal Study of Aging. Am J Respir Crit Care Med 1998;158(5 Pt 1):1459-1464.
34. Borg G. Psychophysical basis of perceived exertion. Med Sci Sports Exerc 1982;14(5):377-381.

35. Caiozzo VJ, Davis JA, Ellis JF, Azus JL, Vandagriff R, Prietto CA, McMaster WC. A comparison of gas exchange indices used to detect the anaerobic threshold. J Appl Physiol 1982;53(5):1184-1189.

36. Wasserman K, Stringer WW, Casaburi R, Koike A, Cooper CB. Determination of the anaerobic threshold by gas exchange: biochemical considerations, methodology and physiological effects. Z Kardiol 1994;83(Suppl 3):1-12.

37. Beaver WL, Wasserman K, Whipp BJ. A new method for detecting anaerobic threshold by gas exchange. J Appl Physiol 1986;60(6): 2020-2027.

38. Balady GJ, Arena R, Sietsema K, Myers J, Coke L, Fletcher GF, et al. Clinician's guide to cardiopulmonary exercise testing in adults: a scientific statement from the American Heart Association. Circulation 2010;122(2):191-225.

39. Skrypnik D, Bogdański P, Mạdry E, Karolkiewicz J, Ratajczak M, Kryściak J, et al. Effects of endurance and endurance strength training on body composition and physical capacity in women with abdominal obesity. Obesity Facts 2015;8(3):175-187.

40. Silva HJ, Andersen LB, Lofrano-Prado MC, Barros MV, Freitas IF Jr, Hill J, Prado WL. Improvements on cardiovascular diseases risk factors in obese adolescents: a randomized exercise intervention study. J Phys Act Health 2015;12(4):553-560.

41. Faul F, Erdfelder E, Lang AG, Buchner A. G* Power 3: A flexible statistical power analysis program for the social, behavioral, and biomedical sciences. Behav Res Methods 2007;39(2):175-191.

42. Cohen J. Statistical power analysis for the behavioral sciences, 2nd ed, Abingdon-on-Thames, United Kingdom: Routledge; 1988:19-74.

43. Womack CJ, Harris DL, Katzel LI, Hagberg JM, Bleecker ER, Goldberg AP. Weight loss, not aerobic exercise, improves pulmonary function in older obese men. J Gerontol A Biol Sci Med Sci 2000; 55(8):M453-M457.

44. Arena R, Cahalin LP. Evaluation of cardiorespiratory fitness and respiratory muscle function in the obese population. Prog Cardiovasc Dis 2014;56(4):457-464.

45. Casaburi R, Porszasz J, Burns MR, Carithers ER, Chang RS, Cooper CB. Physiologic benefits of exercise training in rehabilitation of patients with severe chronic obstructive pulmonary disease. Am J Respir Crit Care Med 1997;155(5):1541-1551.

46. Lorenzo S, Babb TG. Ventilatory responses at peak exercise in endurance-trained obese adults. Chest 2013;144(4):1330-1339.

47. Thomas PS, Cowen ER, Hulands G, Milledge JS. Respiratory function in the morbidly obese before and after weight loss. Thorax 1989;44(5):382-386.

48. Wise RA, Enright PL, Connett JE, Anthonisen NR, Kanner RE, Lindgren $\mathrm{P}$, et al. Effect of weight gain on pulmonary function after smoking cessation in the Lung Health Study. Am J Respir Crit Care Med 1998;157(3 Pt 1):866-872.

49. Bruce CR, Thrush AB, Mertz VA, Bezaire V, Chabowski A, Heigenhauser GJ, Dyck DJ. Endurance training in obese humans improves glucose tolerance and mitochondrial fatty acid oxidation and alters muscle lipid content. Am J Physiol Endocrinol Metab 2006;291(1): E99-E107.

50. Mendelson M, Michallet AS, Perrin C, Levy P, Wuyam B, Flore P. Exercise training improves breathing strategy and performance during the six-minute walk test in obese adolescents. Respir Physiol Neurobiol 2014;200:18-24.

51. El-Gamal H, Khayat A, Shikora S, Unterborn JN. Relationship of dyspnea to respiratory drive and pulmonary function tests in obese patients before and after weight loss. Chest 2005;128(6):3870-3874.

52. Koppers RJ, Vos PJ, Boot CR, Folgering HT. Exercise performance improves in patients with COPD due to respiratory muscle endurance training. Chest 2006;129(4):886-892. 


\section{Ventilatory Efficiency After Endurance Exercise}

53. Babb TG, Buskirk ER, Hodgson JL. Exercise end-expiratory lung volumes in lean and moderately obese women. Int J Obes 1989; 13(1):11-19.

54. Illi SK, Held U, Frank I, Spengler CM. Effect of respiratory muscle training on exercise performance in healthy individuals: a systematic review and meta-analysis. Sports Med 2012;42(8):707-724.

55. Kellerman BA, Martin AD, Davenport PW. Inspiratory strengthening effect on resistive load detection and magnitude estimation. Med Sci Sports Exerc 2000;32(11):1859-1867.

56. Lisboa C, Villafranca C, Leiva A, Cruz E, Pertuzé J, Borzone G. Inspiratory muscle training in chronic airflow limitation: effect on exercise performance. Eur Respir J 1997;10(3):537-542.

57. Powers SK, Criswell D. Adaptive strategies of respiratory muscles in response to endurance exercise. Med Sci Sports Exerc 1996;28(9): 1115-1122.

58. de Carvalho CC, de Sá Xerita Maux DA, Tashiro T, de Moraes SR. The effect of endurance training on the neovascularization of skeletal musculature. Acta Cir Bras 2006;21(6):398-401.

59. Enright S, Chatham K, Ionescu AA, Unnithan VB, Shale DJ. Inspiratory muscle training improves lung function and exercise capacity in adults with cystic fibrosis. Chest 2004;126(2):405-411.

60. Weiner P, Waizman J, Weiner M, Rabner M, Magadle R, Zamir D. Influence of excessive weight loss after gastroplasty for morbid obesity on respiratory muscle performance. Thorax 1998;53(1):39-42.

61. Bhammar DM, Stickford JL, Bernhardt V, Babb TG. Effect of weight loss on operational lung volumes and oxygen cost of breathing in obese women. Int J Obes 2016;40(6):998-1004.

62. Whitelaw WA, Derenne JP. Airway occlusion pressure. J Appl Physiol 1993;74(4):1475-1483.

63. Chlif M, Keochkerian D, Choquet D, Vaidie A, Ahmaidi S. Effects of obesity on breathing pattern, ventilatory neural drive and mechanics. Respir Physiol Neurobiol 2009;168(3):198-202.

64. Bellemare F, Grassino A. Effect of pressure and timing of contraction on human diaphragm fatigue. J Appl Physiol 1982;53(5):1190-1195.
65. Tobin MJ, Chadha TS, Jenouri G, Birch SJ, Gazeroglu HB, Sackner MA. Breathing patterns. 2. Diseased subjects. Chest 1983;84(3):286294.

66. Bellemare F, Grassino A. Force reserve of the diaphragm in patients with chronic obstructive pulmonary disease. J Appl Physiol 1983; 55(1 Pt 1):8-15.

67. Broxterman RM, Ade CJ, Wilcox SL, Schlup SJ, Craig JC, Barstow TJ. Influence of duty cycle on the power-duration relationship: observations and potential mechanisms. Respir Physiol Neurobiol 2014; 192:102-111.

68. McConnell AK, Griffiths LA. Acute cardiorespiratory responses to inspiratory pressure threshold loading. Med Sci Sports Exerc 2010; 42(9):1696-1703.

69. Field S, Sanci S, Grassino A. Respiratory muscle oxygen consumption estimated by the diaphragm pressure-time index. J Appl Physiol Respir Environ Exerc Physiol 1984;57(1):44-51.

70. Killian KJ. Sense of effort and dyspnoea. Monaldi Arch Chest Dis 1998;53(6):654-660.

71. American Thoracic Society. Dyspnea: mechanisms, assessment, and management: a consensus statement. Am J Respir Crit Care Med 1999;159(1):321-340.

72. el-Manshawi A, Killian KJ, Summers E, Jones NL. Breathlessness during exercise with and without resistive loading. J Appl Physiol 1986;61(3):896-905

73. Refsum HE, Holter PH, Løvig T, Haffner JF, Stadaas JO. Pulmonary function and energy expenditure after marked weight loss in obese women: observations before and one year after gastric banding. Int J Obes 1990;14(2):175-183

74. Babb TG, Wyrick BL, Chase PJ, Delorey DS, Rodder SG, Feng MY, Ranasinghe KG. Weight loss via diet and exercise improves exercise breathing mechanics in obese men. Chest 2011;140(2):454-460.

75. Bernhardt V, Babb TG. Weight loss reduces dyspnea on exertion in obese women. Respir Physiol Neurobiol 2014;204:86-92. 